\title{
Body Image in older, inpatient women, and the relationship to BMI, anxiety, depression and other sociodemographic factors
}

\section{Dr Elspeth Dean ${ }^{1}$, Dr Cilla Haywood ${ }^{2}$, A/Prof Peter Hunter ${ }^{3}$, Ms Nicole Austin ${ }^{4}$,} A/Prof Luke Prendergast ${ }^{5}$

${ }^{1}$ Rehabilitation and Aged Care Services, Alfred Health, Melbourne

${ }^{2}$ Rehabilitation and Aged Care Services, Northern Health; Metabolic Disorders Unit, Austin Hospital; University of Melbourne, Melbourne

${ }^{3}$ Rehabilitation and Aged Care Services, Alfred Health, Melbourne

${ }^{4}$ Research Support Coordinator: Business \& Strategy Unit, Alfred Health, Melbourne ${ }^{5}$ Department of Mathematics and Statistics; La Trobe University, Melbourne

\section{Please send correspondence to:}

Dr Elspeth Dean

elspeth.dean@gmail.com

26 Brickwood Street, Brighton, VIC, 3186

Acknowledgements: No funding to declare.

Conflicts of Interest: All authors have no conflicts of interest to declare.

Ethics approved by the Alfred Health Ethics Committee HREC, 7/12/2015, project number 545/15.

\begin{abstract}
Objectives: To determine the prevalence of body image dysfunction in a cohort of older, inpatient women, and to examine any associated health or socio-demographic factors.
\end{abstract}

Methods: In this cross-sectional, observational study, 50 older women admitted to a subacute hospital completed the Body Shape Questionnaire (BSQ-34), Geriatric Depression Screen (GDS), and Geriatric Anxiety Index (GAI). Additional sociodemographic and health-related data including Body Mass Index (BMI) was collected on all participants.

This js the author manuscript accepted for publication and has undergone full peer review but has not been through the copyediting, typesetting, pagination and proofreading process, which may examine factors significantly associated with hody image impairment partial the dis article as doorifelation atgabyse3 3Nere initially performed between BSQ-34 score and included

This article is protected by copyright. All rights reserved. 
variables, and then a stepwise regression analysis was undertaken to determine significantly contributing independent variables.

Results: Only 3 out of 50 women displayed body image dysfunction using suggested cut-off scores from the BSQ-34, giving a prevalence rate of only 6\%. After controlling for multiple variables however, both higher GDS score and higher BMI were found to be significantly and independently associated with poorer body image, with the strongest association being between higher BSQ-34 score and higher BMI (Spearman rank $r=0.455, p<0.001$ ). Furthermore, when high BMI and depression occurred together, this association was even greater, accounting for over $50 \%$ of the impact on body image scores $(\mathrm{p}=0.0001)$.

Conclusion: For this small cohort of older, inpatient women, rates of body image dysfunction were low. There did however appear to be an association between poorer body image and higher BMI and depression rates in the group, which may be worth exploring further in less frail, community-dwelling cohorts.

Key words: Body Image, Women, Older, BSQ-34, BMI

\section{INTRODUCTION}

Body image is the perception that a person has of their physical self, and the thoughts and feelings that result from this perception ${ }^{1}$. It plays an important role in psychosocial health, affecting self-confidence, quality of life and health ${ }^{2}$.

Because ideals of beauty are generally represented by youth, little is known about body image in older people or the effect that ageing has on this self-perception. It is apparent that physical changes associated with the normal ageing process such as involuntary fluctuations in weight, greying and thinning of hair, reduced muscle tone, and deformities resulting from medical illness may exacerbate inadequacies in body image $^{3}$, however literature published to date is conflicting, with some studies showing lower levels of body dissatisfaction and a decrease in the importance of physical appearance with age $e^{4-7}$, and others suggesting that body image continues to be an issue $^{8-12}$. 
For women in particular, societal standards of attractiveness are more influencing than for men ${ }^{13,14}$. Compared to men, women recognise thinner ideal bodies, think more about their own body shape, and perceive their own bodies to be too big ${ }^{11,12}$. Additionally, there is a perception that women in western cultures tend to gain status and value through appearance, whilst men gain status through wealth and power ${ }^{15}$, attributes which are independent of physicality, and which tend to increase with age. Thus it can be argued that ageing may increase older women's susceptibility to body image disturbance more so than men.

Specifically, in comparison to younger women, older women have been found to experience less anxiety regarding their appearance ${ }^{6,14}$, less societal pressure to be thin, and less restricted eating ${ }^{7,9}$. In relative terms however, body image in older women appears to be affected more by weight and the fear of weight gain ${ }^{5,8,16,17}$. Regardless of weight, older women still desire to lose weight, and modify their behaviour to prevent weight gain ${ }^{10,18,19-21}$. One study showed that up to half of a healthy cohort of community-dwelling women aged between 60-70 were currently engaging in dieting, despite being normal weight (BMI 18.5-24.9) ${ }^{10}$.

This knowledge of body image in older women is important, as positive body image is associated with more social engagement, higher self-esteem and better physical functioning $^{22}$. In contrast, body image dysfunction, as well as higher BMI and disordered eating have been associated with higher levels of anxiety, and higher scores on depression screening tests in middle-aged and older cohorts of women with eating disorders ${ }^{23,24}$. As depression and anxiety are known to impact negatively on cognition and quality of life ${ }^{25}$, as well as overall health and mortality ${ }^{26}$, this raises important questions about body image in older women in general.

\section{Objectives}

This pilot study was designed to establish the prevalence of body image dysfunction in a cohort of older, inpatient women via the Body Shape Questionnaire (BSQ-34); to determine the effect of BMI, sociodemographic, health and functional variables on body image in this demographic, and whether depression or anxiety may be associated with deviations from normal. 


\section{METHODOLOGY}

\section{Study design and population}

Inpatient women, aged $\geq 65$, admitted to either a geriatric evaluation and management (GEM) unit or inpatient rehabilitation unit of Caulfield Hospital, Melbourne, were recruited for this cross-sectional, observational study. Caulfield Hospital is a large 220 bed metropolitan, subacute hospital in Victoria, which provides 4 GEM wards, and 4 Rehabilitation wards.

\section{Screening and Recruitment}

Participants were screened via bed access lists, and were approved by the principal investigator. Women were excluded if they were non-english speaking, if they had a Mini Mental Status Examination (MMSE) score from the current admission of $<24$, or if they were amputees as it was felt that this would not only interfere with obtaining an accurate body mass index, but may also unduly influence body image.

\section{Procedure}

Three questionnaires were administered; the Body Shape Questionnaire-34 (BSQ$34)^{27}$, the Geriatric Depression Scale (GDS) ${ }^{28}$ short-form, and the Geriatric Anxiety Inventory $(\mathrm{GAI})^{29}$. Sociodemographic, health and functional data was also collected on each participant, primarily from inpatient notes and documentation, but otherwise directly from the participant. Level of mobility was used as a surrogate measure of functional status, in particular the need for assistance.

Height and weight were collected in order to calculate Body Mass Index (BMI). This was determined by dividing weight $(\mathrm{kg})$ by height $\left(\mathrm{m}^{2}\right)$ in meters squared, and scored as per the World Health Organisation (WHO) with overweight corresponding to a BMI of $25-29.9 \mathrm{~kg} / \mathrm{m}^{2}$, Obese to a BMI of $\geq 30 \mathrm{~kg} / \mathrm{m}^{2}$, and Morbidly Obese to a BMI of $>35 \mathrm{~kg} / \mathrm{m}^{2}$. If data on height and weight was not available, then the participant was 
physically weighed and measured. If an accurate height was unable to be obtained due to physical restrictions i.e. inability to stand or stand straight, then demi-span was used as a proxy measure. Demi-span is the distance from the middle of the sternal notch to the tip of the middle finger when the arm is horizontal and in line with the shoulders. It has been shown to be a reliable tool in estimating height in the elderly with a correlation coefficient of $r=0.86(p<0.0001)^{30}$.

Comorbidity burden and ten-year mortality as determined by the Charlson Comorbidity Index $(\mathrm{CCI})^{31}$, was collected for each participant, as well as current and premorbid functional status.

\section{Body Shape Questionnaire (BSQ-34)}

The BSQ-34 is a 34-item, self-report measure of body shape and weight preoccupation originally developed to determine body image disturbance among women $^{32}$. It asks questions such as "Have you been so worried about your shape that you have been feeling you ought to diet" and "Have you felt ashamed of your body". Each item is scored from 1 to 6 with "Never" $=1$ and "Always" $=6$, and total score is out of 204. It has shown concurrent validity with other measures of body image ${ }^{32}$, and has been validated for use in older and elderly women, amongst different clinical and cultural groups, and has been shown to demonstrate good test-retest reliability $(\mathrm{r}=$ $0.94)$, internal consistency $(r=0.95)$ and convergent validity ${ }^{33}$. It has not been validated for use in cognitively impaired women.

There is no consensus on how to interpret scores from the body shape questionnaire. Crude cut-off points have suggested that $<81$ correlates with no body image impairment, 81-110 with mild body image impairment, 111-140 with moderate body image impairment, and >140 with severe body image impairment, however there is no validated level between "normal" and "abnormal" 32 , and scores have variously been analysed as both categorical and continuous data.

\section{SAMPLE SIZE}

This study was intended as a pilot study only and therefore, a convenience sample of 50 women was recruited. 


\section{ETHICS}

Full ethics approval was obtained from the Alfred Hospital Human Research Ethics Committee HREC.

\section{STATISTICAL ANALYSIS}

To describe and summarise the cohort, means and standard deviations as well as medians and interquartile ranges were reported. Due to a limited sample size however, the statistical analysis focussed on several variables thought to be of interest to the subject of body image. Some categorical variables that were not included in the main analysis due to a very small number of individuals in one or more categories, may be of interest in any subsequent analysis following this pilot study and are therefore also discussed.

Partial correlations were reported between BSQ score and the selected numeric variables to determine the strength of the relationship and to control for confounding variables. Spearman rank correlations were reported due to normality violations. Residual plots following the regression analysis revealed non-normality of error and heteroscedasticity, problems that were alleviated by using a natural log transformation of the dependent variable. Therefore, this approach was used and estimated coefficients and confidence intervals were returned to original scale using the exponential transformation. Results were then interpreted as percentage increases per unit increase in the independent variable. Stepwise variable selection was used to simplify the model so as to focus on those variables that contributed to explaining variation in the dependent variable. To account for multiple comparisons, a family-wise confidence level of $95 \%$ was used for the confidence intervals for the regression coefficients and the p-values were adjusted accordingly.

Significance was reported for $\mathrm{p}<0.05$.

Analysis was performed using SPSS Version 20.

\section{RESULTS}


50 participants were recruited by the primary investigator from 64 approached. The most common reasons for non-participation were not being in the room, lack of interest, feeling too unwell or feeling that language skills weren't good enough. No data was missing from recruited participants.

Sample characteristics are reported in Table 1. The median and IQR for several continuous variables indicated the presence of skew (e.g. GDS score, GAI score and MMSE) which will be accounted for in the analysis. For the total group, participants had a mean $[ \pm \mathrm{SD}]$ age of 83.3 [ \pm 7.4$]$, and a median (IQR) BMI of 25.3 [20.8-29.6], with $26 \%$ of participants overweight, $10 \%$ obese, and $14 \%$ morbidly obese. The majority of participants were not working (94\%), living in an urban area (94\%), and were either non-mobile or requiring assistance with mobility (92\%). Just over half were Australian born (62\%), 44\% had finished high school, and six percent of the total group had achieved tertiary education.

Using the categorical cutoff BSQ-34 score of $<81$, only 3 participants displayed impaired body image, giving a prevalence rate for body image impairment of only $6 \%$ (Table 2).

After controlling for variables via partial correlation, only GDS score and BMI were found to be significantly positively associated with higher body image impairment scores, with the strongest association being between BSQ-34 score and higher BMI (Spearman rank $\mathrm{r}=0.455, \mathrm{p}<0.001)$ (Table 3). A subsequent stepwise regression analysis, that also included an indicator variable identifying whether the subject was born in Australia, retained GDS Score, BMI and the indicator variable as contributing independent variables. The estimated model using these variables accounted for more than half of the variation in BSQ-34 scores (Adjusted $\mathrm{R}^{2}=54.4 \%$ ). Controlling for multiple comparisons, both GDS Score and BMI were significant ( $\mathrm{p}=0.007$ and $\mathrm{p}<$ 0.001). Each unit increase in GDS score is estimated to result in a mean BSQ-34 score of 3.4\% (95\% CI [0.7 - 6.1]) and a unit increase in BMI a mean BSQ-34 score increase of $2.5 \%$ (95\% CI [1.5 - 3.5]). It may also be that those who are Australian born are expected to have, on average, lower BSQ-34 scores (estimated mean BSQ-34 $13.2 \%$ lower, $95 \%$ CI [-1.9 - 26], $\mathrm{p}=0.099)$.

Finally, a Spearman rank correlation analysis to determine any association between 
BMI and GDS was performed, which showed that BMI and GDS scores were not significantly associated with each other $(r=0.13, p=0.37)$, and therefore were each independently associated with body image impairment.

\section{DISCUSSION}

It was hypothesised that body image dysfunction would be present in this cohort of older women. Of the 50 participants included however, only 3 displayed impaired body image, giving a prevalence rate for body image impairment of $6 \%$. Although appropriate comparative outcomes are lacking, this rate still seems very low. Similar studies examining body image in older women have shown prevalence rates for poor satisfaction with weight or shape of between $25 \%$ and $65 \%$, rates significantly higher than those seen in this study.

One explanation for this discrepancy in rates of body image impairment could be the age of participants. The average age of participants in the current study was 83.3, which is considerably older than participants in the few other studies that have explored body image in older women, with mean ages in these studies ranging from $59-72^{8,10}$.

A more likely explanation is that participants in the current study were inpatients on geriatric rehabilitation wards, and therefore were more unwell and more functionally limited than participants in other similar studies. Most participants in the current study required assistance with mobility, slightly less required assistance prior to admission, and a small percentage usually resided in residential care. The average Charlson Comorbidity score equated to a 10 -year survival rate of only $2.25 \%$. In comparison, participants in other similar studies have been predominantly well, community-dwelling women, who were independently mobile and motivated ${ }^{8,10}$. Body Image has been described as dynamic ${ }^{7,13}$, and intuitively it can be understood as a constantly changing concept that is highly affected by past and current personal circumstances. In the context of being faced with illness, admission to hospital, loss of function and the possibility of not returning home, most people are likely to value health and independence over appearance. In this sense, it can be postulated that participants in the current study likely had bigger concerns than their body image. 
Outcomes of sociocultural influences on body image impairment in this study also differed to others. Although literature to date has shown that education is an important influencer of desired weight, no such association was found in the current study. In fact no significant association was found between body image and either education levels, employment status or religion. Again, this may have reflected either the low participant numbers or functional limitations of participants in the current study.

The major outcome from this study was the finding of a significant association between greater body image impairment and higher BMI and depression levels. This is consistent with literature to date which has suggested that body image in older women is more likely to be influenced by weight than any other factor, and that older women who are overweight or obese show less satisfaction with their body ${ }^{10}$, are more likely to be dieting or to want to lose weight ${ }^{5}$, and importantly have higher levels of depression and anxiety ${ }^{24,25}$. Although a post-hoc analysis showed that depression and BMI are not significantly associated with each other, causation is not proven by this study, and therefore it is unclear whether women with impaired body image are more prone to obesity or depression, or whether the converse is true and that obesity leads to body image impairment or depression in this demographic. Prior to adjustment poorer body image was also found to be significantly associated with younger age as well as being currently employed (data not shown). It may be that this is reflective of higher levels of independence and community engagement in these participants and lower levels of frailty, which may be considered contributing factors to higher preoccupation with body image, however, this is largely contradicted by the finding that being currently non-mobile had a higher impact on BSQ-34 score than being independent, or requiring assistance. Ultimately, no major insights can be made from these findings given the lack of statistical significance, and the possibility that these conflicting results may reflect the small sample size.

There were a number of limitations to this study. Firstly, the number of included participants was small. Although other studies examining body image in older women have been comparatively small, with participant numbers ranging from 20$288^{11,16,18}$, the limited numbers included in this pilot study meant that it wasn't powered for significance, and potentially resulted in a Type 2 error. If participant 
numbers had been higher, a significant association between body image impairment and other sociodemographic or health-related variables may have been detected. A major difficulty encountered in analysing data from this study was how to score the Body Shape Questionnaire. There is no consensus on how to differentiate between impaired and normal body image, and the suggested cut-off scores are simply estimates based on women as a whole. In particular there is no demographic-related differentiation (e.g. elderly vs adolescent), which may be relevant to consider as the sensitivity of the result may diminish in older age. Furthermore, it seems inaccurate to dismiss body image concern on the basis of 1 or 2 points, and far more appropriate to consider the concept of body image as a spectrum. In literature to date, results from the BSQ-34 have variously been analysed as both categorical and continuous variables, and subsequently it was felt appropriate to analyse BSQ-34 scores from this study in both ways also.

In summary, the small numbers of participants with impaired body image in this study were not significant enough to suggest changing clinical practice, however in older, inpatient women, it may be important to consider body image impairment as an associated factor in those with higher BMIs and co-existent depression. There is enough evidence to suggest that body image still remains a significant issue for women aged over 65 in general, and this pilot study lends itself further, to larger studies in the area.

\section{CONCLUSION}

For older, inpatient women, rates of body image impairment are low. When present however, body image impairment appears to be significantly associated with higher BMI, and higher scores on Geriatric Depression Scale testing. Larger studies looking at body image impairment in less functionally impaired cohorts of older women would be valuable.

\section{IMPACT STATEMENT}

\section{Practice Impact}

Although rates of Body Image dysfunction appear to be low for older, inpatient women, it should still be an important factor considered in those in this demographic 
who are both depressed and overweight. Further research looking at a less frail cohort of older women, may be useful in determining just how strong this association is in older women in general.

\section{DATA AVAILABILITY STATEMENT}

The data that support the findings of this study are available from the corresponding author upon reasonable request.

\section{REFERENCES}

1. National Eating Disorders Collaboration. Australian Department of Health and Ageing. 2011

2. Peat CM, Peyer NL, Muehlenkamp JJ. Body image and eating disorders in older adults: A review. Journal of General Psychology. 2008; 135:343-358

3. Chrisler JC, Ghiz L. Body Image Issues of Older Women. Women \& Therapy. 1993; 14(1-2):67-75

4. Öberg P, Tornstam L. Body images among men and women of different ages. Ageing \& Society. 1999; 19: 629-644

5. Hetherington MM, Burnett L. Ageing and the pursuit of slimness: Dietary restraint and weight satisfaction in elderly women. British Journal of Clinical Psychology. 1994; 33:391-400

6. Reboussin BA, Rejeski WJ, Martin KA, Callahan K, Dunn AL, King AC. Correlates of satisfaction with body function and body appearance in middle age and older aged adults: The Activity Counseling Trial (ACT). Psychology \& Medicine. 2000; 15:239-254

7. Tiggemann M, Lynch JE. Body image across the life span in adult women: the role of self-objectification. Developmental Psychology. 2001; 37:243-253

8. Allaz AF, Bernstein M, Rouget P, Archinard M, Morabai A. Body Weight Preoccupation in Middle-Age and Ageing Women: A General Population Survey. International Journal of Eating Disorders. 1998; 23:287-294

9. Lewis DM, Cachelin FM. Body image, body dissatisfaction, and eating attitudes in midlife and elderly women. Eat Disord. 2001 Spring; 9(1):29-39

10. Mangweth-Matzek B, Rupp CL, Hausmann A, et al. Never Too Old for Eating Disorders or Body Satisfaction: A Community Study of Elderly Women. 
International Journal of Eating Disorders. 2006; 39(7):583-6

11. Ferraro FR, Muehlenkamp JJ, Paintner A et al. Aging, Body Image and Body Shape. The Journal of General Psychology. 2008; 135(4):379-392

12. Rozin P, Fallon A. Body image, attitudes to weight, and misperceptions of figure preferences of the opposite sex: A comparison of men and women in two generations. Journal of Abnormal Psychology. 1988; 97:342-345

13. Pliner P, Chaike, S, Flett G. Gender differences in concern with body weight and physical appearance over the life span. Personality and Social Psychology Bulletin. 1990; 16, 263-273

14. Franzoi SL, Koehler V. Age and gender differences in body attitudes: a comparison of young and elderly adults. The International Journal of Aging and Human Development. 1998; 47(1):1-10

15. Wilcox, S. (1997). Age and gender in relation to body attitudes: Is there a double standard of aging? Psychology of Women Quarterly, 21, 549-565

16. Pruis TA, Janowsky JS. Assessment of body image in younger and older women. The Journal of General Psychology: Experimental, Psychological, and Comparative Psychology. 2010; 137(3):225-238

17. Gosselink CA, Cox DL, McClure SJ, De Jong ML. Ravishing or ravaged: women's relationships with women in the context of aging and Western beauty culture. International Journal of Aging and Human Development. 2008; $66: 307-32$

18. Dixon JB, Dixon ME, O’Brien PE. Body image: appearance orientation and evaluation in the severely obese. Changes with weight loss. Obes Surg. Feb; 2002 12(1):65-71

19. Rodin J, Silberstein L, Striegel-Moore R. Women and weight: A normative discontent. Psychology and gender. 1985; 5:267-307

20. Foster GD, Wadden TA, Vogt RA. Body image in obese women before, during, and after weight loss treatment. Health Psychol. May 1997; 16(3):226229

21. Adami GF, Gandolfo P, Campostano A, et al. Body image and body weight in obese patients. Int J Eat Disord. Nov; 1998 24(3):299-306

22. Kleinspehn-Ammerlahn, A., Kotter-Gruhn, D., \& Smith, J. (2008). Selfperceptions of aging: Do subjective age and satisfaction with aging change during old age? Journal of Gerontology: Psychological Sciences,63B, P377- 
P385

23. Guerdjikova AI, O’Melia AM, Mori N, McCoy J, McElroy S. Binge eating disorder in elderly individuals. International Journal of Eating Disorders 2012; 45:905-908

24. Forman, M., \& Davis, W. N. (2005). Characteristics of middle-aged women in inpatient treatment for eating disorders. Eating Disorders, 13, 231-243

25. Berkman, L., Berkman, C., Kasl, S., Freeman, D. H., Leo, L., Ostfeld, A. M., Cornoni-Huntley, J., \& Brody, J. A. (1986). Depressive symptoms in relation to physical health and functioning in the elderly. American Journal of Epidemiology, 124, 372-388

26. Glass, T. A., DeLeon, C. F. M., Bassuk, S. S., \& Berkman, L. F. (2006). Social engagement and depressive symptoms in late life: Longitudinal findings. Journal of Aging and Health,18, 604-627

27. Cooper, Taylor, Cooper and Fairburn. Body Shape Questionnaire. 1987

28. Sheikh JI, Yesavage JA. Geriatric Depression Scale (GDS); Recent evidence and development of a shorter version. Clinical Gerontologist. 1986; 5:165-173

29. Pachana NA, Byrne GJ eet al. Development and validation of the Geriatric Anxiety Inventory. International Journal of Pyschogeriatrics. 2007 Feb; 19(1):103-14

30. Hickson, M. Frost, G. (2003). A comparison of three methods for estimating height in the acutely ill elderly population. Journal Hum Nutr Diet. Feb 16(1):13-20

31. Charlson ME, Pompei P, Ales KL, MacKenzie CR. A new method of classifying prognostic comorbidity in longitudinal studies: development and validation. Journal of Chronic Disease. 1987; 40(5):373-83

32. Cooper PJ, Taylor MJ, Cooper M, Fairburn CG. The development and validation of the Body Shape Questionnaire. International Journal of Eating Disorders. 1987; 6:485-494

33. Rosen JC, Jones A, Ramirez E, Waxman S. Body Shape Questionnaire: studies of validity and reliability. Int J Eat Disord. 1996 Nov; 20(3):315-9

This article is protected by copyright. All rights reserved. 


\section{TABLES}

Table 1.

Sample summary; mean (SD - standard deviation), median (IQR - interquantile range) for continuous variables and category percentages for categorical variables.

\begin{tabular}{|c|c|c|c|}
\hline Variable & Mean (SD) & Median (IQR) & $\%$ \\
\hline Age & $83.3(7.4)$ & $84(79-89)$ & \\
\hline GDS Score & $4.1(3.1)$ & $3(2-6)$ & \\
\hline GAI Score & $3.5(5.0)$ & $1(0-5)$ & \\
\hline BMI & $26.7(8.1)$ & $25.3(20.9-29.1)$ & \\
\hline MMSE & $27.5(2.0)$ & $27(26-30)$ & \\
\hline CCI & $5.78(1.753)$ & $6(4-7)$ & \\
\hline Australian Born* & & & $62 \%$ \\
\hline Residence ** & & & $94 \%$ \\
\hline Eating disorder**** & & & $2 \%$ \\
\hline Employment status***** & & & $6 \%$ \\
\hline \multicolumn{4}{|l|}{ Regligion } \\
\hline - Christianity & & & $62 \%$ \\
\hline - Orthodox & & & $4 \%$ \\
\hline - Judaism & & & $12 \%$ \\
\hline - No religion & & & $22 \%$ \\
\hline \multicolumn{4}{|l|}{ Marital Status } \\
\hline - Married & & & $22 \%$ \\
\hline - Divorced & & & $14 \%$ \\
\hline - Never Married & & & $6 \%$ \\
\hline - Widowed & & & $58 \%$ \\
\hline \multicolumn{4}{|l|}{ Living situation } \\
\hline - Alone & & & $60 \%$ \\
\hline - With family & & & $36 \%$ \\
\hline - Residential Care & & & $4 \%$ \\
\hline \multicolumn{4}{|l|}{ Education Level } \\
\hline - Less than High School & & & $56 \%$ \\
\hline - High School & & & $22 \%$ \\
\hline - Technical College & & & $16 \%$ \\
\hline - Degree & & & $6 \%$ \\
\hline Smoking & & & \\
\hline - Never & & & $60 \%$ \\
\hline - Current & & & $6 \%$ \\
\hline$-E x$ & & & $34 \%$ \\
\hline Alcohol & & & \\
\hline - Current & & & $6 \%$ \\
\hline - Non-drinker & & & $94 \%$ \\
\hline Australian Born $(1=y c$ & & & \\
\hline Residence (1=urban, & & & \\
\hline $\begin{array}{ll}* * * & \text { Eating disorder }(1=\mathrm{ye} \\
* * * * & \text { Employment status } 1\end{array}$ & & & \\
\hline
\end{tabular}

Table 2.

Classification of participants by Body Shape Questionnaire (BSQ) score BSQ score Number of participants

Not worried about body shape $(<81) \quad 47(94 \%)$

Slightly worried (81-110) $1(2 \%)$ 
Moderately worried (111-140)

$1(2 \%)$

Severely worried $(>140)$

$1(2 \%)$

Table 3.

Partial correlations between BSQ score and continuous variables; Stepwise regression estimates (\% change) following a stepwise variable selection procedure.

\begin{tabular}{|lll|}
\hline Independent Variable & Partial Correlation & Stepwise Regression Estimate $^{* * *}$ \\
\hline Age & $-0.118(\mathrm{p}=0.440)$ & \\
GDS Score & $\mathbf{0 . 3 1 5}(\mathbf{p}=\mathbf{0 . 0 3 5})$ & $\mathbf{3 . 4}(\mathbf{0 . 7}, \mathbf{6 . 1}) \mathbf{p}=\mathbf{0 . 0 0 7}$ \\
GAI Score & $0.012(\mathrm{p}=0.937)$ & \\
BMI & $\mathbf{0 . 4 5 5}(\mathbf{p}=\mathbf{0 . 0 0 2})$ & $\mathbf{2 . 5}(\mathbf{1 . 5}, \mathbf{3 . 5}) \mathbf{p}<\mathbf{0 . 0 0 1}$ \\
Functional Status & $0.062(\mathrm{p}=0.686)$ & \\
Australian born & & $-13.2(-26.0,1.9) \mathrm{p}=0.099$ \\
\hline
\end{tabular}

Spearman rank correlations

Estimated regression model coefficients (CIs in parentheses)

This article is protected by copyright. All rights reserved. 


\section{University Library}

\section{- M M N E R VA A gateway to Melbourne's research publications}

Minerva Access is the Institutional Repository of The University of Melbourne

Author/s:

Dean, E;Haywood, C;Hunter, P;Austin, N;Prendergast, L

Title:

Body image in older, inpatient women and the relationship to BMI, anxiety, depression, and other sociodemographic factors

Date:

2019-12-02

Citation:

Dean, E., Haywood, C., Hunter, P., Austin, N. \& Prendergast, L. (2019). Body image in older, inpatient women and the relationship to BMI, anxiety, depression, and other sociodemographic factors. INTERNATIONAL JOURNAL OF GERIATRIC PSYCHIATRY, 35 (2), pp.182-187. https://doi.org/10.1002/gps.5233.

Persistent Link:

http://hdl.handle.net/11343/286699 